\title{
Neonatal hypoglycemic brain injury is a cause of infantile spasms
}

\author{
GUANG YANG $^{1,2}$, LI-PING ZOU ${ }^{1,3}$, JING WANG $^{1}$, XIUYU SHI $^{1}$, SHUPING TIAN ${ }^{4}$, \\ XIAOFAN YANG ${ }^{1}$, JUN JU ${ }^{1}$, HONGXIANG YAO ${ }^{4}$ and YUJIE LIU ${ }^{1}$ \\ ${ }^{1}$ Department of Pediatrics, Chinese PLA General Hospital, Beijing 100853; ${ }^{2}$ Department of Pediatrics, \\ Hainan Branch of Chinese PLA General Hospital, Sanya, Hainan 572013; ${ }^{3}$ Department of Neurology, \\ Beijing Children's Hospital, The Capital Medical University, Beijing 100045; ${ }^{4}$ Department of Radiology, \\ Chinese PLA General Hospital, Beijing 100853, P.R. China
}

Received December 17, 2014; Accepted February 11, 2016

DOI: 10.3892/etm.2016.3107

\begin{abstract}
Neonatal hypoglycemic brain injury is one of the causes of infantile spasms. In the present study, the clinical history and auxiliary examination results of 18 patients who developed infantile spasms several months after neonatal hypoglycemia were retrospectively analyzed. Among the 666 patients with infantile spasms admitted to two pediatric centers between January 2008 and October 2012, 18 patients developed infantile spasms after being diagnosed with neonatal hypoglycemia, defined as a whole blood glucose concentration of $<2.6 \mathrm{mmol} / 1$. These patients developed infantile spasms from between 2 and 10 months (mean, 4.9 months) following the diagnosis of neonatal hypoglycemia. All 18 patients had abnormal electroencephalographic findings with either classical or modified hypsarrhythmia. Upon examination using brain magnetic resonance imaging (MRI), 10 patients (55.6\%) exhibited abnormalities. The MRI results principally showed a disproportional involvement of parietal and occipital cortices and sub-cortical white matter lesions. In conclusion, the results of this study indicate that neonatal hypoglycemic brain injury is associated with the subsequent development of infantile spasms.
\end{abstract}

\section{Introduction}

Infantile spasms are an age-specific epileptic encephalopathy occurring in early infancy that are characterized by epileptic spasms with neurodevelopmental regression and electroencephalographic (EEG) features of hypsarrhythmia $(1,2)$. The incidence of infantile spasms is $\sim 0.31$ per 1,000 live births $(3,4)$. The average age of onset of infantile spasms is

Correspondence to: Professor Li-Ping Zou, Department of Pediatrics, Chinese PLA General Hospital, 28 Fuxing Road, Beijing 100853, P.R. China

E-mail: zouliping21@hotmail.com

Key words: infantile spasms, neonatal hypoglycemia, brain injury, etiology
6 months (with a peak age of onset of 3-7 months), and the prevalence is slightly higher in males $(5,6)$.

Pathophysiological mechanisms underlying infantile spasms remain elusive; two-thirds of patients have brain insults, and $>200$ different etiologies have been found to be involved in the pathogenesis of infantile spasms (7). Neonatal hypoglycemia is the most common metabolic disorder during the neonatal period and is a recognized trigger of infantile spasms (8-10). Previous studies have found that neonatal hypoglycemia may result in hypoglycemic neurological injuries, also known as neonatal hypoglycemic brain injuries (11-16). Udani et al examined the etiology of remote symptomatic epilepsy with onset during the first 3 years of life and observed that neonatal hypoglycemia was the most common etiology, with spasms being the most common type of seizure (14).

Although hypoglycemic brain injury induces infantile spasms, few cases of patients with neonatal hypoglycemia who subsequently developed infantile spasms have been reported $(9,10)$. The present study describes the clinical findings for 18 infants with neonatal-onset hypoglycemia who later presented with infantile spasms, which suggest that neonatal hypoglycemia is potentially associated with the subsequent occurrence and development of infantile spasms during infancy.

\section{Materials and methods}

Patients. Data on 666 children with infantile spasms admitted to the Chinese PLA General Hospital and Beijing Children's Hospital affiliated with Capital Medical University (Beijing, China) from January 2008 to October 2012 were retrospectively analyzed. The study was approved by the Ethics Committee of the Chinese PLA General Hospital. Written informed consent was obtained from all patients included in the study.

Diagnosis of infantile spasms. The diagnostic criteria for infantile spasms were as follows: i) the presence of epileptic spasms; ii) hypsarrhythmia or modified hypsarrhythmia on EEG recordings (NicoletOne Ambulatory EEG; Cardinal Health, Inc., Dublin, OH, USA) prior to treatment; and iii) age of onset of the infantile spasms between 1 month and 2 years (1). Hypsarrhythmia was characterized by EEG findings showing a chaotic background with nearly continuous random 
asynchronous high-voltage slow waves and spikes arising from multiple foci. Modified hypsarrhythmia was defined as the presence of any of the following: Hypsarrhythmia with increased interhemispheric synchronization, asymmetric hypsarrhythmia, hypsarrhythmia with a consistent focus of abnormal discharge, hypsarrhythmia with episodes of voltage attenuation, and hypsarrhythmia with small spikes or sharp activity (17).

Diagnosis of neonatal hypoglycemia. Neonatal hypoglycemia was confirmed by laboratory results during the neonatal period based on a review of medical records. Hypoglycemia was defined as a condition in which the whole blood glucose concentration was $<2.6 \mathrm{mmol} / \mathrm{l}(18)$.

Seizure analysis. Seizure semiology was analyzed based on clinical history, contact with parents or caregivers, and video-EEG recordings. All patients received long-term video-EEG recordings and neuroradiological investigations following the onset of spasms but prior to antiepileptic treatment. For the majority of patients, magnetic resonance imaging (MRI; GE Signa EXCITE 1.5T MRI machine; GE Healthcare Life Sciences, Chalfont, UK) of the brain was repeated more than once to better clarify the tomography of lesions. These retrospective data were collected by two of the authors (Dr Shi and Dr Wang); the retrospective study protocol was stringently followed so that no bias was introduced in this process. The final brain MRI images were analyzed by two different authors (Dr Tian and Dr Yao), who are experienced neuroradiologists, in order to benefit from the optimum imaging quality and to identify the precise extent of chronic brain damage.

\section{Results}

Case selection. Among the 666 diagnosed cases of infantile spasm, 22 patients suffered from neonatal hypoglycemia with a whole blood glucose concentration of $<2.6 \mathrm{mmol} / \mathrm{l}$ during the neonatal period. Among these 22 patients, 4 cases were excluded, comprising 2 patients who presented with perinatal asphyxia, 1 patient who had brain malformations, and 1 patient who exhibited a chromosome abnormality. These complications identified in the 4 patients might have jointly contributed to the subsequent spasms. Among the recruited 18 patients, there were 16 boys, and 2 girls. Seventeen of the patients were full-term infants at birth, whereas one was premature. Once the diagnosis of neonatal hypoglycemia was confirmed, glucose was immediately supplemented intravenously. The case selection process is presented in Fig. 1.

Risk factors. With regard to the risk factors of the 18 cases of neonatal hypoglycemia, there were 6 cases with poor feeding, 5 cases with diabetic mothers, 3 cases afflicted by neonatal swallowing syndrome, 1 preterm infant, and 3 cases with no clear cause. All these subjects were confirmed to have neonatal hypoglycemia at 1-4 days after birth. Neonatal seizures were observed in 5/18 (27.8\%) children prior to the development of infantile spasms. The patients developed infantile spasms at a range of 2 to 10 months (mean, 4.9 months) after the diagnosis of neonatal hypoglycemia, which is consistent with previously reported data (6). The detailed clinical data on these 18 cases are presented in Table I.

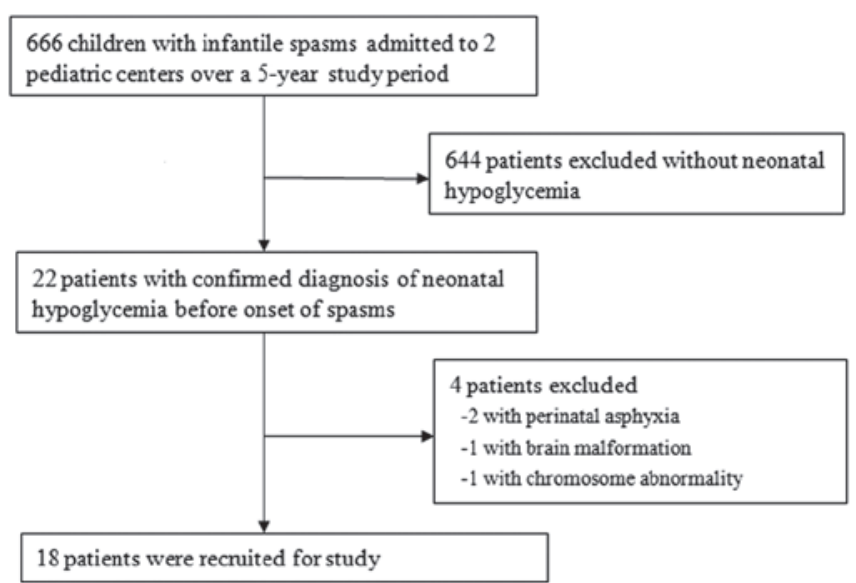

Figure 1. Flow diagram of the case selection progress.

EEG results. The video-EEG results of these patients prior to antiepileptic treatment were analyzed, and all 18 patients exhibited abnormal EEG findings. The interictal EEG recordings of 12 patients $(66.7 \%)$ revealed classical hypsarrhythmia, whereas those of the other 6 patients $(33.3 \%)$ exhibited modified hypsarrhythmia.

MRI examination. Upon brain MRI examination, 8 patients $(44.4 \%)$ had structurally normal brains. However, the images of the other 10 patients $(55.6 \%)$ were abnormal, primarily showing disproportionate involvement of the parietal and occipital cortices and sub-cortical white matter lesions. In case 16, the brain MRI showed bilateral parieto-occipital encephalomalacia foci (Fig. 2).

\section{Discussion}

Infantile spasms are an age-specific epileptic syndrome associated with diverse etiological factors. Patients with infantile spasms often have poor developmental outcomes. Extensive and broad categories of etiologies, including prenatal, perinatal, and postnatal insult, have been involved in the pathogenesis of infantile spasms. Furthermore, almost any brain abnormality or injury can potentially cause infantile spasms (7).

Neonatal hypoglycemic brain injury is a cause of infantile spasms. However, few large systematic studies have been conducted to characterize the association of neonatal hypoglycemic brain injury with infantile spasms. The lack of glucose can selectively impair multiple brain regions, including the superficial cortex, dentate gyrus, hippocampus, and caudate putamen; this impairment occurs through several putative mechanisms, such as the release of excitatory neurotransmitter (19), increased mitochondrial free radical generation and initiation of apoptosis (20), activation of neuronal nicotinamide adenine dinucleotide phosphate (NADPH) oxidase (21), and altered cerebral energetic characteristics $(22,23)$. In one study in which the etiology of remote symptomatic epilepsy with onset during the first 3 years of life was examined, it was observed that neonatal hypoglycemia was the most common etiology, and infantile spasms were the most common type of seizure (14). 
Table I. Clinical data on 18 patients with infantile spasms after neonatal hypoglycemia.

\begin{tabular}{|c|c|c|c|c|c|c|c|}
\hline $\begin{array}{l}\text { Case } \\
\text { no. }\end{array}$ & Gender & $\begin{array}{l}\text { Age at onset } \\
\text { of spasms } \\
\text { (months) }\end{array}$ & $\begin{array}{l}\text { Birth } \\
\text { status }\end{array}$ & $\begin{array}{l}\text { Age at onset } \\
\text { of NH } \\
\text { (days) }\end{array}$ & $\begin{array}{l}\text { Neonatal } \\
\text { seizures }\end{array}$ & EEG results & Brain MRI results \\
\hline 1 & Male & 3 & Full term & 2 & No & Hypsarrhythmia & $\begin{array}{l}\text { Bilateral corona radiata and } \\
\text { occipital abnormal signal } \\
\text { intensity }\end{array}$ \\
\hline 2 & Male & 8 & Preterm & 2 & No & Hypsarrhythmia & $\begin{array}{l}\text { Bilateral centrum semiovale } \\
\text { abnormal signal intensity }\end{array}$ \\
\hline 3 & Female & 5 & Full term & 3 & Yes & $\begin{array}{l}\text { Modified } \\
\text { hypsarrhythmia }\end{array}$ & $\begin{array}{l}\text { Bilateral parieto-occipital } \\
\text { cystic damage }\end{array}$ \\
\hline 4 & Male & 4 & Full term & 3 & No & Hypsarrhythmia & Normal \\
\hline 5 & Male & 4 & Full term & 2 & Yes & Hypsarrhythmia & Left occipital cystic damage \\
\hline 6 & Male & 3.5 & Full term & 3 & No & Hypsarrhythmia & Normal \\
\hline 7 & Male & 6 & Full term & 2 & No & Hypsarrhythmia & $\begin{array}{l}\text { Bilateral occipital polycystic } \\
\text { damage }\end{array}$ \\
\hline 8 & Male & 2 & Full term & 2 & No & Modified hypsarrhythmia & Normal \\
\hline 9 & Male & 4 & Full term & 4 & Yes & Modified hypsarrhythmia & Normal \\
\hline 10 & Male & 7 & Full term & 3 & No & Hypsarrhythmia & $\begin{array}{l}\text { Bilateral occipital } \\
\text { periventricular white matter } \\
\text { abnormal signal intensity }\end{array}$ \\
\hline 11 & Male & 4 & Full term & 2 & No & Hypsarrhythmia & $\begin{array}{l}\text { Right parieto-occipital cyst } \\
\text { damage }\end{array}$ \\
\hline 12 & Female & 10 & Full term & 1 & No & Hypsarrhythmia & Normal \\
\hline 13 & Male & 5 & Full term & 3 & Yes & Hypsarrhythmia & $\begin{array}{l}\text { Bilateral occipital polycystic } \\
\text { damage }\end{array}$ \\
\hline 14 & Male & 6 & Full term & 4 & No & Modified hypsarrhythmia & Normal \\
\hline 15 & Male & 4 & Full term & 3 & No & Hypsarrhythmia & Normal \\
\hline 16 & Male & 6 & Full term & 2 & No & Hypsarrhythmia & $\begin{array}{l}\text { Bilateral parieto-occipital } \\
\text { cystic damage }\end{array}$ \\
\hline 17 & Male & 4 & Full term & 2 & Yes & Modified hypsarrhythmia & $\begin{array}{l}\text { Bilateral parieto-occipital and } \\
\text { right temporal cystic damage }\end{array}$ \\
\hline 18 & Male & 2 & Full term & 3 & No & Modified hypsarrhythmia & Normal \\
\hline
\end{tabular}

NH, neonatal hypoglycemia; EEG, electroencephalographic; MRI, magnetic resonance imaging.

Infantile spasms following exposure to neonatal hypoglycemia are relatively rare and, to the best of our knowledge, have been described in only two previous reports with a total of 6 patients $(9,10)$. In the present study, the clinical, biochemical, EEG, and neuroradiological characteristics of 18 patients with neonatal-onset hypoglycemia who subsequently developed infantile spasms are reported. This case series suggests that neonatal hypoglycemic brain injury could be an underlying cause of infantile spasms later in the infancy period. The latency period of infantile spasms following the onset of neonatal hypoglycemia was 2-10 months in this case series, and epileptogenic neutral circuits could be formed during this period. This finding is consistent with previous observations that the duration of latency between the onset of insult and the development of infantile spasms is variable $(9,24)$. This temporal latency may be explained by the developmental desynchronization hypothesis, which is that an insult results in desynchronization of the development between the abnormal cortical areas and the subcortical structures. This desynchronization disrupts normal functional interactions and becomes increasingly important as the brain matures, resulting in a functional deficit that causes infantile spasms (25).

In our previous studies, which involved an animal model of NMDA-induced stress and clinical epidemiological analysis, it was found that prenatal adverse stress is associated with infantile spasms $(26,27)$. Shi et al (28) proposed a hypothesis (known as Zou's hypothesis) of prenatal stress exposure for infantile spasms. This hypothesis states that diverse etiological factors, for example, brain dysplasia and inherited metabolic diseases, are the foundations for the onset of infantile spasms, whereas adverse stress occurring during the perinatal period causes the onset of infantile spasms. Moreover, the mutual effects of these two aspects may cause the occurrence of infantile spasms. A close association exists between neonatal hypoglycemia and stress. Adverse perinatal stress is an important cause of neonatal hypoglycemia $(29,30)$. A study conducted in newborn piglets 

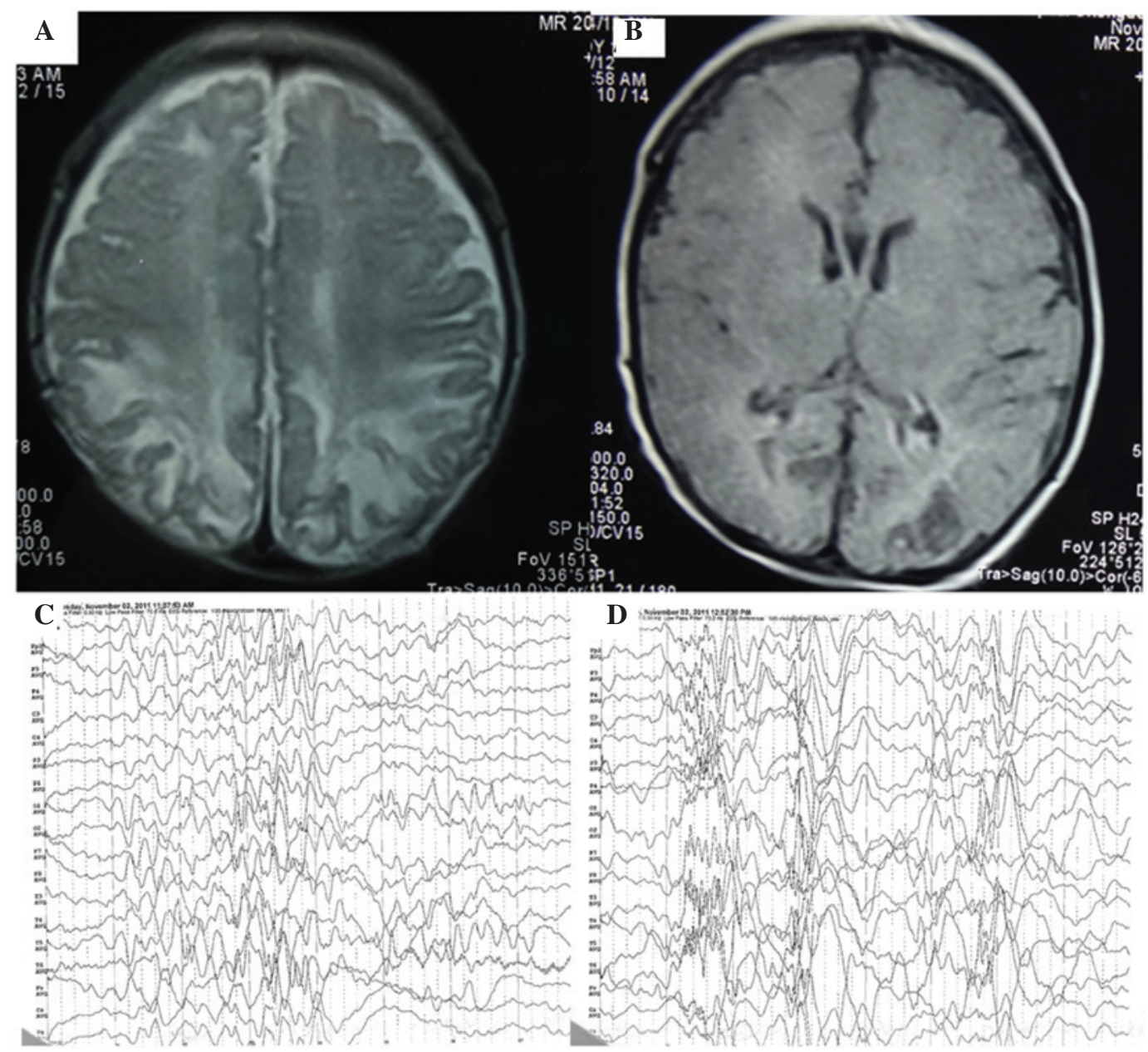

Figure 2. Brain magnetic resonance imaging (MRI) and electroencephalographic (EEG) images of a subject with infantile spasms. (A) Axial T2- and (B) T1-weighted MRI demonstrating the bilateral parieto-occipital encephalomalacia foci. (C and D) EEG showing classical hypsarrhythmia.

has demonstrated that neonatal hypoglycemia may also affect the functions of brain cells by causing specific changes in the cerebral N-methyl-D-aspartate receptor-associated ion channel, which may subsequently trigger spasms (31).

With regard to the cause of the 18 cases of neonatal hypoglycemia in the present study, the majority of these cases were exposed to various risk factors, including a diabetic mother, delayed feeding, neonatal swallowing syndrome and prematurity. Delayed feeding may be one reason that some healthy term neonates were hypoglycemic. Some newborns were not given formula milk or sweet water in the few hours after birth, even if the mother's breast milk was lacking because of the promotion of breastfeeding by the government. Although hyperinsulinemic hypoglycemia has been listed as an etiology of infantile spasms, the insulin levels for those patients with neonatal hypoglycemia were not examined for the patients in the present study.

In the present study, all 18 patients had abnormal EEG findings with either classical or modified hypsarrhythmia. Moreover, more than half of the patients (55.6\%) presented abnormal MRI results. Because of the complexity of a newborn's circumstances, other factors that may dispose to brain injury, such as asphyxia, premature birth, low birth weight and maternal factors complicated the clinical case study. However, in 10 cases with MRI anomalies, all showed occipital white matter damage, consistent with hypoglycemic injury to susceptible parts of the brain mentioned in the literature $(16,23)$; therefore, it was considered these MRI changes were mainly induced by hypoglycemia. Previous studies have reported that structural and functional cortical abnormalities in patients with infantile spasms have a predilection for posterior brain areas $(32,33)$. In the present study, MRI neuroimaging principally showed a disproportionate involvement of parietal and occipital cortices and sub-cortical white matter lesions.

The significance of this study is that it provides clinical evidence that neonatal hypoglycemic brain injury is an important cause of infantile spasms. Whether timely treatment of hypoglycemia will prevent the onset of infantile spasms and poor developmental outcome is uncertain, but a better understanding of the pathophysiological linking between neonatal hypoglycemia and infantile spasms could result in the development of more effective neuroprotective strategies. This study highlights the potential risks of neonatal hypoglycemia, particularly in inadequately treated patients, and it must be emphasized that close neurological follow-up is important in children who suffer from neonatal hypoglycemia. 


\section{Acknowledgements}

This study was supported by grants from the Major State Basic Research Development Program (973 Program; grant no. 2012CB517903), the National Natural Science Foundation of China (grant nos. 30770747,30801249, 81071036 and 81211140048), the Beijing Municipal Natural Science Foundation (grant nos. 7142150 and 7081002), the Capital Development Foundation of Beijing (grant no. 2003-2037), the CapitalCharacteristicClinicalApplicationResearchFoundation (grant no. Z121107001012056), the Hygiene Industry-Specific Research Projects of China (grant no. 200802074), the Sanya Municipal Scientific and Technological Innovation Project in Health Care (grant no. 2014YW41) and the Science and Technology Special Fund for Social Development of Hainan Province (grant no. 2015SF05).

\section{References}

1. Pellock JM, Hrachovy R, Shinnar S, Baram TZ, Bettis D, Dlugos DJ, Gaillard WD, Gibson PA, Holmes GL, Nordl DR, et al: Infantile spasms: A US consensus report. Epilepsia 51: 2175-2189, 2010.

2. Lux AL: Latest American and European updates on infantile spasms. Curr Neurol Neurosci Rep 13: 334, 2013.

3. Pavone P, Striano P, Falsaperla R, Pavone L and Ruggieri M: Infantile spasms syndrome, West syndrome and related phenotypes: What we know in 2013. Brain Dev 36: 739-751, 2014.

4. Trevathan E, Murphy CC and Yeargin-Allsopp M: The descriptive epidemiology of infantile spasms among Atlanta children. Epilepsia 40: 748-751, 1999.

5. Go CY, Mackay MT, Weiss SK, Stephens D, Adams-Webber T, Ashwal S and Snead OC III; Child Neurology Society; American Academy of Neurology: Evidence-based guideline update: Medical treatment of infantile spasms. Report of the Guideline Development Subcommittee of the American Academy of Neurology and the Practice Committee of the Child Neurology Society. Neurology 78: 1974-1980, 2012.

6. Hrachovy RA and Frost JD Jr: Infantile spasms. Handb Clin Neurol 111: 611-618, 2013.

7. Osborne JP, Lux AL, Edwards SW, Hancock E, Johnson AL, Kennedy CR, Newton RW, Verity CM and O'Callaghan FJ: The underlying etiology of infantile spasms (West syndrome): Information from the United Kingdom infantile spasms study (UKISS) on contemporary causes and their classification. Epilepsia 51: 2168-2174, 2010.

8. Yu JY and Pearl PL: Metabolic causes of epileptic encephalopathy. Epilepsy Res Treat 2013: 124934, 2013.

9. Camurdan MO, Cinaz P, Serdaroğlu A, Bideci A and Demirel F: Persistent hyperinsulinemic hypoglycemia presenting with a rare complication: West syndrome. J Pediatr Endocrinol Metab 17: 1465-1468, 2004.

10. Kumaran A, Kar S, Kapoor RR and Hussain K: The clinical problem of hyperinsulinemic hypoglycemia and resultant infantile spasms. Pediatrics 126: e1231-e1236, 2010.

11. Rozance PJ: Update on neonatal hypoglycemia. Curr Opin Endocrinol Diabetes Obes 21: 45-50, 2014.

12. Boardman JP, Wusthoff CJ and Cowan FM: Hypoglycaemia and neonatal brain injury. Arch Dis Child Educ Pract Ed 98: 2-6, 2013.
13. Vijay K and Agarwal A: Neonatal hypoglycemia resulting in occipital cerebral injury. Pediatr Radiol 40 (Suppl 1): S178, 2010.

14. Udani V, Munot P, Ursekar M and Gupta S: Neonatal hypoglycemic brain-injury a common cause of infantile onset remote symptomatic epilepsy. Indian Pediatr 46: 127-132, 2009.

15. Montassir H, Maegaki Y, Ogura K, Kurozawa Y, Nagata I, Kanzaki S and Ohno K: Associated factors in neonatal hypoglycemic brain injury. Brain Dev 31: 649-656, 2009.

16. Termote B, Verswijvel G, Gelin G and Palmers Y: Neonatal hypoglycemic brain injury. JBR-BTR 91: 116-117, 2008.

17. Jain P, Sharma S and Tripathi M: Diagnosis and management of epileptic encephalopathies in children. Epilepsy Res Treat 2013: 501981, 2013.

18. Harris DL, Weston PJ, Signal M, Chase JG and Harding JE: Dextrose gel for neonatal hypoglycaemia (the Sugar Babies Study): A randomised, double-blind, placebo-controlled trial. Lancet 382: 2077-2083, 2013.

19. Papagapiou MP and Auer RN: Regional neuroprotective effects of the NMDA receptor antagonist MK-801 (dizocilpine) in hypoglycemic brain damage. J Cereb Blood Flow Metab 10: 270-276, 1990.

20. Ballesteros JR, Mishra OP and McGowan JE: Alterations in cerebral mitochondria during acute hypoglycemia. Biol Neonate 84: 159-163, 2003.

21. Suh SW, Gum ET, Hamby AM, Chan PH and Swanson RA Hypoglycemic neuronal death is triggered by glucose reperfusion and activation of neuronal NADPH oxidase. J Clin Invest 117: 910-918, 2007.

22. Imai $\mathrm{T}$, Kondo $\mathrm{M}$, Isobe $\mathrm{K}$, Itoh $\mathrm{S}$ and Onishi S: Cerebral energy metabolism in insulin induced hypoglycemia in newborn piglets: In vivo ${ }^{31} \mathrm{P}$-nuclear magnetic resonance spectroscopy. Acta Paediatr Jpn 38: 343-347, 1996.

23. Wong DS, Poskitt KJ, Chau V, Miller SP, Roland E, Hill A and Tam EW: Brain injury patterns in hypoglycemia in neonatal encephalopathy. AJNR Am J Neuroradiol 34: 1456-1461, 2013.

24. Guggenheim MA, Frost JD Jr and Hrachovy RA: Time interval from a brain insult to the onset of infantile spasms. Pediatr Neurol 38: 34-37, 2008

25. Frost JD Jr and Hrachovy RA: Pathogenesis of infantile spasms: A model based on developmental desynchronization. J Clin Neurophysiol 22: 25-36, 2005.

26. Shang NX, Zou LP, Zhao JB, Zhang F and Li H: Association between prenatal stress and infantile spasms: A case-control study in China. Pediatr Neurol 42: 181-186, 2010.

27. Zou LP, Zhang WH, Wang HM, Zen M, Chen K and Mix E: Maternal IgG suppresses NMDA-induced spasms in infant rats and inhibits NMDA-mediated neurotoxicity in hippocampal neurons. J Neuroimmunol 181: 106-111, 2006.

28. Shi XY, Zou LP, Yang G and Ding YX: Prenatal stress exposure hypothesis for infantile spasms. Med Hypotheses 78: 735-737, 2012.

29. Nold JL and Georgieff MK: Infants of diabetic mothers. Pediatr Clin North Am 51: 619-37, 2004.

30. Najati $\mathrm{N}$ and Saboktakin L: Prevalence and underlying etiologies of neonatal hypoglycemia. Pak J Biol Sci 13: 753-756, 2010.

31. McGowan JE, Zanelli SA, Haynes-Laing AG, Mishra OP and Delivoria-Papadopoulos M: Modification of glutamate binding sites in newborn brain during hypoglycemia. Brain Res 927: 80-86, 2002

32. Chugani HT, Shewmon DA, Shields WD, Sankar R, Comair Y, Vinters HV and Peacock WJ: Surgery for intractable infantile spasms: Neuroimaging perspectives. Epilepsia 34: 764-771, 1993.

33. Hamano S, Tanaka M, Kawasaki S, Nara T, Horita H, Eto Y and Kohno S: Regional specificity of localized cortical lesions in West syndrome. Pediatr Neurol 23: 219-224, 2000. 